ARTICLE

\title{
Stimuli-controlled self-assembly of diverse tubular aggregates from one single small monomer
}

\author{
Qixun Shi ${ }^{1,2}$, Tomas Javorskis ${ }^{3}$, Karl-Erik Bergquist ${ }^{1}$, Artūras Ulčinas ${ }^{4}$, Gediminas Niaura ${ }^{5}$, leva Matulaitiené ${ }^{5}$,
} Edvinas Orentas $^{3} \&$ Kenneth Wärnmark ${ }^{1}$

The design and synthesis of new stimuli-responsive hydrogen-bonding monomers that display a diversity of self-assembly pathways is of central importance in supramolecular chemistry. Here we describe the aggregation properties of a simple, intrinsically $\mathrm{C}_{2}$-symmetric enantiopure bicyclic cavity compound bearing a terminally unsubstituted ureidopyrimidinone fragment fused with a pyrrole moiety in different solvents and in the absence and presence of $C_{60}$ and $C_{70}$ guests. The tetrameric cyclic aggregate is selectively obtained in chlorinated solvents, where only part of the available hydrogen bonding sites are utilized, whereas in toluene or upon addition of $\mathrm{C}_{70}$ guests, further aggregation into tubular supramolecular polymers is achieved. The open-end cyclic assemblies rearrange into a closed-shell capsule upon introduction of $\mathrm{C}_{60}$ with an accompanied symmetry breaking of the monomer. Our study demonstrates that a $\mathrm{C}_{60}$ switch can be used to simultaneously control the topology and occupancy of tubular assemblies resulting from the aggregation of small monomers.

\footnotetext{
${ }^{1}$ Center for Analysis and Synthesis, Department of Chemistry, Lund University, Lund SE-221 00, Sweden. ${ }^{2}$ Institute of Advanced Synthesis, School of Chemistry and Molecular Engineering, Jiangsu National Synergetic Innovation Center for Advanced Materials, Nanjing Tech University, Nanjing 211816, China. ${ }^{3}$ Department of Organic Chemistry, Vilnius University, Vilnius LT-03225, Lithuania. ${ }^{4}$ Department of Nanoengineering, Center for Physical Sciences and Technology, Vilnius LT-02300, Lithuania. ${ }^{5}$ Department of Organic Chemistry, Center for Physical Sciences and Technology, Vilnius LT-10257, Lithuania. Correspondence and requests for materials should be addressed to E.O. (email: edvinas.orentas@chf.vu.lt) or to K.W. (email: kenneth.warnmark@chem.lu.se).
} 
T he careful design of the shape of the monomer and the relative position of the hydrogen-bonding ( $\mathrm{H}$-bonding) motifs are prerequisites for the construction of supramolecular H-bonded assemblies that possess a cavity with tailormade properties ${ }^{1,2}$. To assure a reliable assembly profile leading to the formation of the desired cavity and to lower the entropic cost of the process, covalent synthesis is often used to a large extent to spatially locate the basic constitutional elements and control the dimensions of the cavity. Impressive examples of selfassembling capsules based on both coordination and H-bonds have been reported with the cavity size ranging from almost negligible to giant $\left(>10,000 \AA^{3}\right.$; ref. 3$)$ and with the shape from almost ideally spherical to non-symmetrical, such as the 'banana'-

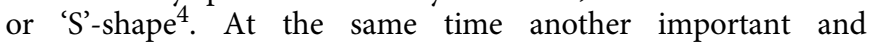
structurally related topology, $\mathrm{H}$-bonded organic nanotubes, has recently been addressed ${ }^{5-8}$; however, with limited success in terms of the generality and simplicity of the strategy for the self-assembly process. As a rule, more structurally elaborated monomers give more predictable outcomes of the self-assembly, but unfortunately at the expense of synthetic efforts involved in their preparation. This is reasonable taking into account the entropic cost needed to assemble a large number of small monomers and the increase of the number of alternative aggregation pathways when several less preorganized monomers are used. All these challenges make it of highest interest to develop small and thus easily available monomers that selfassemble into open-end cavity aggregates capable of responding to external stimuli and switching between well-defined open, closed or polymeric forms, all possessing a tubular structure. The successful design of such responsive monomers could lead to switchable self-assembling transmembrane channels for drug delivery, shape-selective catalysts or insulator materials for molecular wires, among many other conceivable possibilities.

To accomplish this task, H-bonds are preferred over coordination bonds due to the more expressed dynamic nature of the former, especially when different conformers and tautomeric forms of the H-bonding unit are engaged in the assembly process. Moreover, for the initially formed cavity aggregate to be able to assemble further to a tube, additional $\mathrm{H}$-bonding sites must be available to connect them into a polymer by rim-to-rim self-assembly (hierarchical self-assembly).

The ureidopyrimidinone (UPy) unit, first introduced by Sijbesma and colleagues 9,10 , represents the most reliable and useful H-bonding motif, extensively used in areas of supramolecular chemistry as diverse as supramolecular polymers ${ }^{11}$, receptors ${ }^{12}$, capsules ${ }^{13}$, chromophore dyads ${ }^{14}$ and even biological applications ${ }^{5}$. In the vast majority of cases, the UPy unit adopts a quadruple self-complementary H-bonding tautomer, that is, an AADD $(\mathrm{A}=\mathrm{H}$-bond acceptor; $\mathrm{D}=\mathrm{H}$-bond donor) unit or the corresponding enolic tautomeric form, DADA (Fig. 1a). This preference, however, could be changed when the electron-rich pyrrole ring is directly fused with UPy (herein referred as PUPy $)^{16}$. Owing to electronic factors, the most stable tautomer becomes the one having the $6[1 \mathrm{H}]$-pyrimidinone form of the isocytosine unit and existing as single conformer, where the terminal urea proton is $\mathrm{H}$-bonded to an isocytosine nitrogen atom (Fig. 1b). In this form, it cannot participate in selfcomplementary quadruple H-bonding, but instead it has several $2 \mathrm{H}$-bonding sites positioned at different angles. Although ditopic hydrogen bonds are usually not very strong, they could be significantly strengthened by their incorporation into cyclic arrays. The high level of preorganization of the monomer for cyclic aggregation could even result in a tautomeric form or a conformer otherwise not observed in simpler congeners. Such aggregation-induced tautomer/conformer shift is expected to be extremely favourable in cyclic systems to fulfill the maximum occupancy of $\mathrm{H}$-bonding sites in response to geometric constraints in the monomer. The use of enantiomerically pure building blocks could further secure the tubular aggregation mode over the open linear one ${ }^{7}$.

Herein we report that by using an enantiomerically pure bicyclic H-bonding monomer, it is possible to access a collection of tubular supramolecular aggregates via interconversion of conformers within the hydrogen-bonding PUPy unit. The previously unobserved conformer of PUPy is shown to be essential in realizing efficient recognition of a $\mathrm{C}_{60}$ guest. The system described herein represents a unique case of a sophisticated stimulus-responsive, dynamic, one-component supramolecular system.

\section{Results}

Monomer design. The design and synthesis of the building blocks, monomers 1 and 2, and the two control compounds 3 and $\mathbf{4}$ are outlined in Fig. 1c-e. Each of the monomer comprises the enantiomerically pure bicyclo[3.3.1]nonane $(\mathrm{BCN})$ framework $^{17-20}$ to which two PUPys, bearing unsubstituted ureas, are attached via fused pyrrole rings. As depicted in Fig. 1c, the use of unsubstituted urea groups is essential to our design, as it introduces a second $2 \mathrm{H}$-bonding site positioned orthogonally to the already existing $2 \mathrm{H}$-bonding site in the isocytosine ring. Although the latter $\mathrm{H}$-bonding site was envisioned to be utilized for the connection of the bicyclic V-shaped monomers into cyclic tetrameric assemblies, the former unsubstituted urea will be required for linking the resulting cyclic tetramers into a $2 \mathrm{H}$-bonded polymeric tube (Fig. 1d). The present design of the monomers aimed at reaching tubular aggregation is built on the results from our previous studies, where we have demonstrated that all attempts to connect cyclic tetrameric units via $\mathrm{H}$-bonds at the rim of the tetramer that are located too close to the bicyclic core were not successful. This is most likely to be due to the steric crowding arising from the bulky solubilizing groups situated on the core ${ }^{20}$. On the other hand, these groups were necessary to ensure solubility of the monomer. We reasoned that these complications could be overcome by placing the H-bonding sites required for tubular polymerization further away from the solubilizing groups using urea functional group as in monomer $\mathbf{1}$ In addition, to secure a cyclic aggregation mode of high fidelity, we used an enantiomerically pure monomer. Monomer 1 was synthesized starting from the easily affordable enantiopure ketone 5 having solubilizing groups attached to the bicyclic framework (Fig. 1e) ${ }^{21}$. The straightforward thermal Fischer indolization of hydrazone 7 delivered intermediate 8 , which was then converted to the target compound $\mathbf{1}$ by the activation of the amino group in the isocytosine ring with phenylchloroformate and the subsequent treatment with ammonia. Monomer 2, having the smaller p-bromobenzyl substituents attached to the BCN framework, was synthesized following the same reaction sequence as above and was needed as a more rigid analogue of $\mathbf{1}$ for atomic force microscopy (AFM) studies (vide infra). The control compound $\mathbf{3}$, containing a larger pyrrole nitrogen substituent, and compound 4 , containing fully substituted terminal urea nitrogen atom, were obtained by modified procedures (Supplementary Fig. 1).

Self-assembly and host-guest studies of monomer 1. Monomer 1 was soluble in a variety of solvents of vastly different polarities, which allowed for the investigation of its aggregation properties in detail. When dissolved in $\mathrm{CDCl}_{3}, \mathbf{1}$ displayed a well-defined ${ }^{1} \mathrm{H}$ nuclear magnetic resonance (NMR) spectrum, suggestive of both the formation of the anticipated tautomeric form of the PUPy units and the formation of one single type of cyclic aggregate through H-bonding (Fig. 2a). Namely, there are four 
a

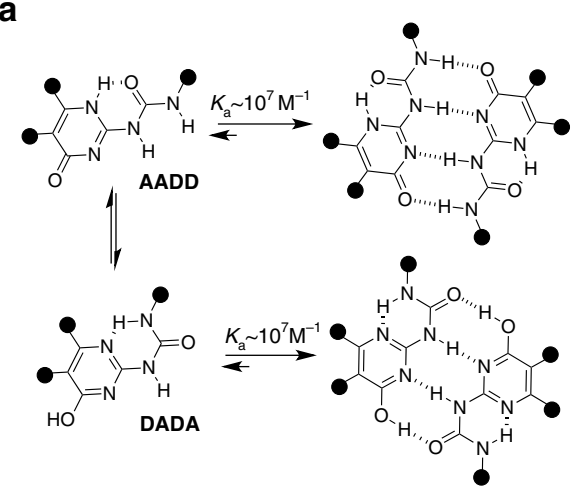

Ureidopyrimidinone (UPy)

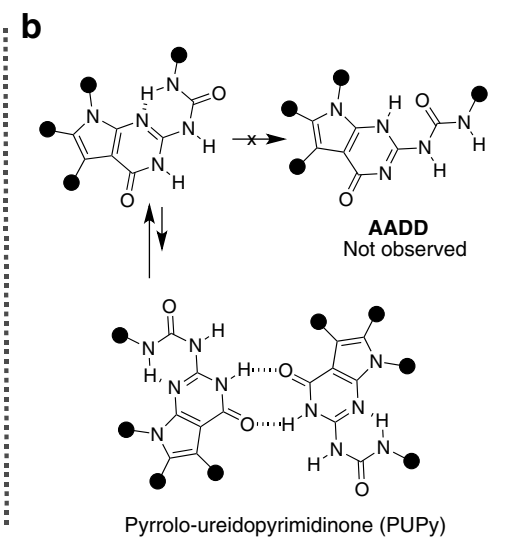

C

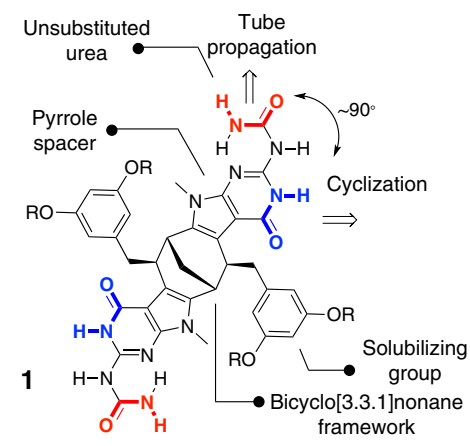

d
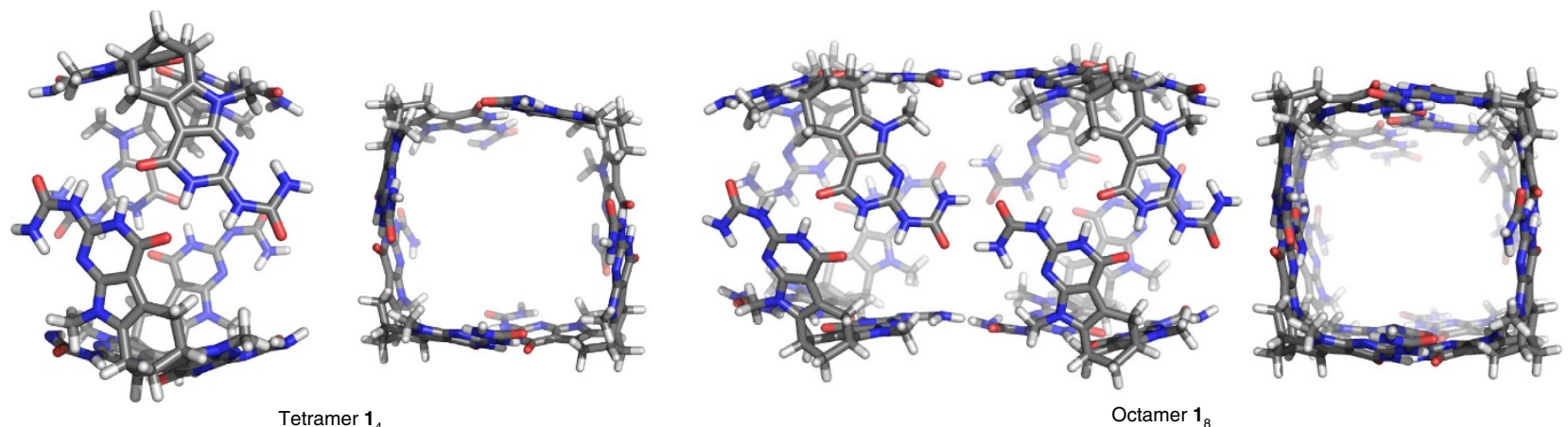

e
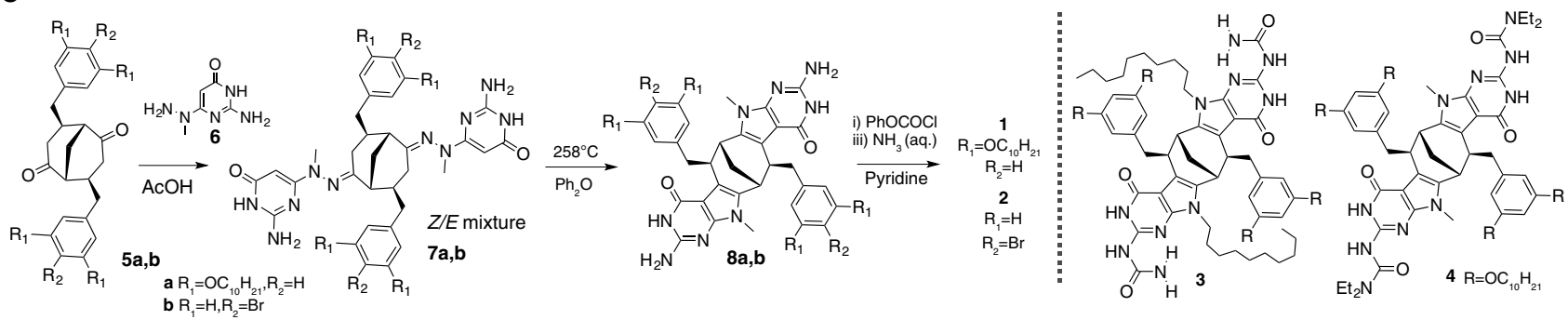

Figure 1 | Monomer design and synthesis. (a) Two self-complementary AADD and DADA UPy tautomers and their exceptionally strong dimerization. (b) The most stable tautomer of PUPy derivatives and their weak dimerization via $2 \mathrm{H}$-bonding. (c) Schematic representation of the essential design elements of supramolecular monomer $\mathbf{1}$, allowing two orthogonal $2 \mathrm{H}$-bonding directions (marked as red and blue). (d) Molecular models of $2 \mathrm{H}$-bonded tetramer $\mathbf{1}_{4}$ and the corresponding tubular polymer assembly, depicted as octamer $\mathbf{1}_{8}$. The solubilizing chains were omitted for clarity. (e) Synthesis of monomers $\mathbf{1}$ and $\mathbf{2}$ having different solubilizing groups and control compounds $\mathbf{3}$ and $\mathbf{4}$.

$\mathrm{NH}$ protons corresponding to a $\mathrm{C}_{2}$-symmetric structure and also indicating restricted rotation of the urea unit due to an intramolecular H-bond ( $\delta 8.88$ p.p.m.) between the pyrimidine $s p^{2} \mathrm{~N}$ atom and the urea proton 1 . The chemical shift of proton 4 ( $\delta$ 13.43 p.p.m.) supports its involvement in intermolecular $\mathrm{H}$-bonding within a cyclic tetramer as originally designed. On the other hand, the chemical shift of the proton 3 ( $\delta$ 7.12 p.p.m.) indicates that this proton is not a part of the $\mathrm{H}$-bonding array (Figs 1c,d and 2a). The unambiguous assignment of all $\mathrm{NH}$ protons was made using several NMR techniques (Supplementary Figs 25-34). Hence, protons 1 and 2 were shown to reside on the same nitrogen atom as evidenced by ${ }^{1} \mathrm{H}-{ }^{15} \mathrm{~N}$ heteronuclear single quantum coherence spectroscopy and site-selective labelling with the ${ }^{15} \mathrm{~N}$ isotope (Supplementary Fig. 32). The strong long-range coupling between protons 2 and 3, separated by four single bonds, was observed in the ${ }^{1} \mathrm{H}-{ }^{1} \mathrm{H}$ correlated (correlation spectroscopy) spectrum and is easily explained as a $\mathrm{W}$-coupling, fully consistent with the geometry of the proposed conformer (Fig. 1c). Moreover, the observed rotating-frame nuclear Overhauser effect correlations between isocytosine protons 3 and 4 , as well as between urea proton 1 and the protons of $N$-methyl group of the pyrrole moiety further corroborated the $\mathrm{AD}-\mathrm{DA}$ arrangement of the $\mathrm{H}$-bonding sites positioned in the right direction for envisioned lateral and longitudinal aggregation of monomer.

To confirm that monomer $\mathbf{1}$ exists as a $\mathrm{H}$-bonded tetramer in $\mathrm{CDCl}_{3}$, we performed diffusion-ordered spectroscopy experiments, which showed a correlation of all the ${ }^{1} \mathrm{H}$ resonances to a single diffusion coefficient, which translated to a hydrodynamic radius, $R_{\mathrm{H}}=10 \AA$, consistent with an aggregate significantly larger than the monomer and in good agreement with the values previously obtained for related tetrameric assemblies (Supplementary Fig. 35) ${ }^{12,18}$. In addition, the high stability of the aggregate in $\mathrm{CDCl}_{3}$ was evidenced from the insensitivity of the $\mathrm{NH}$ proton resonances to dilution or heating, as well as the observation of negligible tailing of the corresponding peak in the gel permeation chromatogram (GPC) (Supplementary Figs 36, 37 and 48 ). The latter confirmed the presence of a single aggregate with polydispersity index $=1.02$. 
a

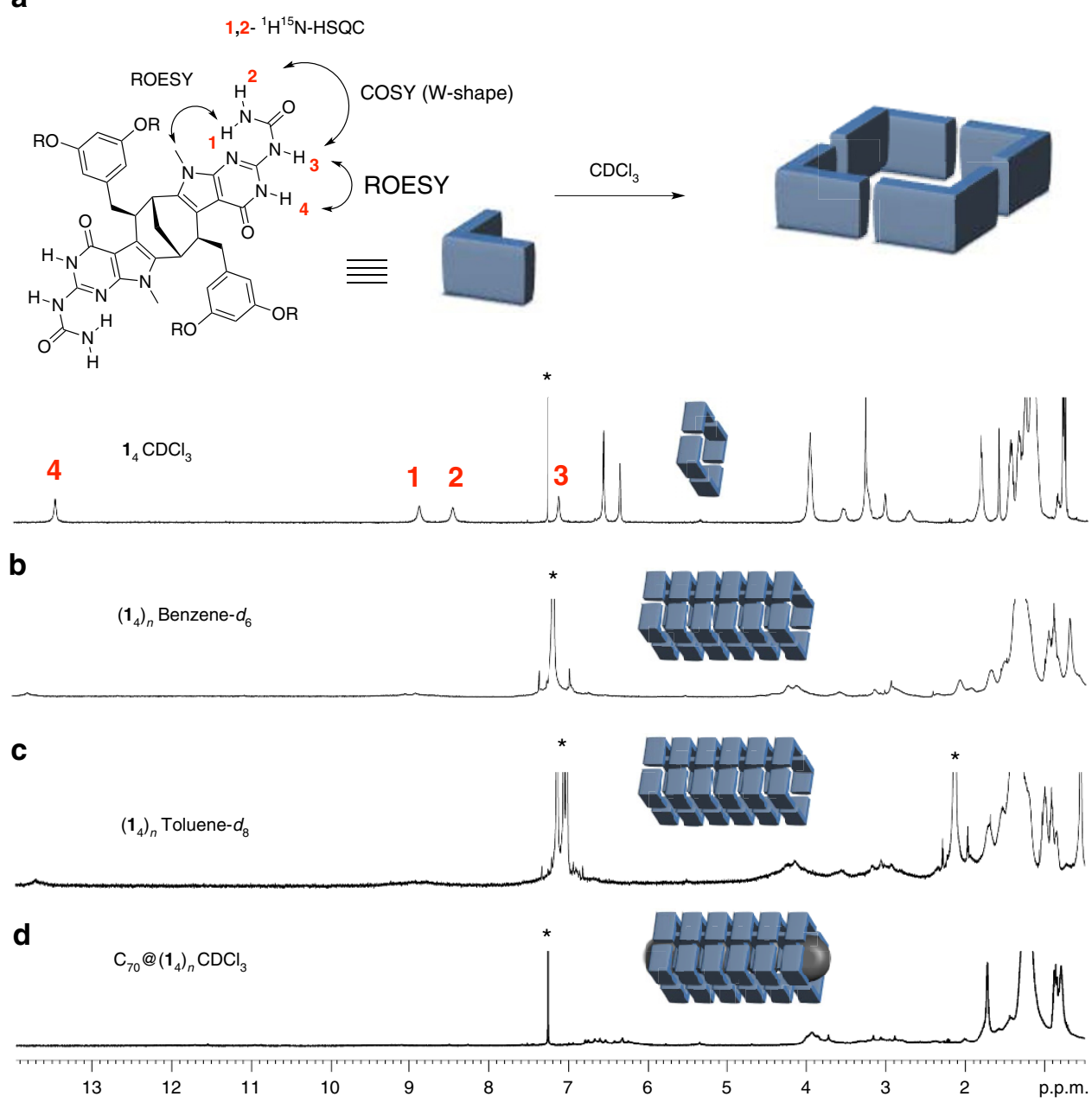

Figure $\left.2\right|^{\mathbf{1}} \mathbf{H}$ NMR spectra of monomer $\mathbf{1}$ in different solvents. (a) ${ }^{1} \mathrm{H}$ NMR characterization of monomer $\mathbf{1}$ in $\mathrm{CDCl}_{3}$. (b) ${ }^{1} \mathrm{H}$ NMR spectrum of $\mathbf{1}$ in benzene- $d_{6}$. (c) ${ }^{1} \mathrm{H}$ NMR spectrum of $\mathbf{1}$ in toluene- $d_{8}$. (d) ${ }^{1} \mathrm{H}$ NMR spectrum of $\mathbf{1}$ in $\mathrm{CDCl}_{3}$ in the presence of $\mathrm{C}_{70}$. ${ }^{*}$ Indicates the residual solvent signal.

Having shown that compound $\mathbf{1}$ exists only as a tetramer in $\mathrm{CDCl}_{3}$, we further reasoned that the anticipated polymer was not formed due to the much weaker $\mathrm{H}$-bonds between terminal urea units as compared with strong intra-cyclic $\mathrm{H}$-bonds. We therefore decreased the polarity of the solvent switching from chlorinated to aromatic solvents, such as toluene and benzene, to increase the strength of the H-bonds. Indeed, the formation of highmolecular-weight aggregates was first detected by the inspection of the ${ }^{1} \mathrm{H}$ NMR spectra, where extreme broadening of the signals and complete disappearance of the $\mathrm{NH}$ resonances were observed, typical for polymeric materials (Fig. 2b,c). Most remarkably, the formation of polymeric aggregates could be triggered even in the more polar $\mathrm{CDCl}_{3}$, when a $\mathrm{C}_{70}$ guest was added (Fig. $\left.2 \mathrm{~d}\right)^{22}$. In both cases, the formation of polymeric aggregates was confirmed by AFM (Fig. 3a,b), dynamic light scattering and GPC analysis (Fig. 3c). According to the dynamic light scattering data, oligomeric assemblies with $R_{\mathrm{H}}=11 \mathrm{~nm}$ and $R_{\mathrm{H}}=20 \mathrm{~nm}$ were formed in toluene and $\mathrm{C}_{70} / \mathrm{CDCl}_{3}$ solution, respectively, corresponding roughly to $15-20$ cyclic tertameric units in the chain (Supplementary Fig. 41). GPC experiments with monomer $\mathbf{1}$ and control compound $\mathbf{3}$ in toluene indicated the formation of supramolecular polymers and a discrete cyclic tetramer, respectively. The fresh solution of $\mathbf{1}$ displayed a bimodal distribution of molecular mass, probably corresponding to a mixture of oligomers and cyclic tetramers (Fig. 3c, blue line). The lower-molecular-weight peak was found to have almost the same retention time as compound $\mathbf{3}$, which can only form tetrameric assemblies $\mathbf{3}_{4}$, due to the steric hindrance between the decyl groups on the pyrrole nitrogen atom of $\mathbf{3}_{4}$ units within polymer $\left(3_{4}\right)_{n}$. During ageing, however, the signal of the cyclic tetramer $\mathbf{1}_{4}$ disappears completely, leading to the formation of highmolecular-weight supramolecular polymers (Fig. 3c, green line). The characterization of the formed supramolecular tubular polymers casted on surface (silicon and mica) from a toluene or a $\mathrm{C}_{70} / \mathrm{CDCl}_{3}$ solution by $\mathrm{AFM}$ revealed fibre-like superstructures where multiple molecular tubes were stacked together side-by-side (Fig. 3a). Decreasing the concentration did not prevent this unwanted aggregation of the tubular aggregates. Therefore, a more rigid analogue of monomer $\mathbf{1}$, that is, compound 2 (Fig. 1e) was used instead. Indeed, although the lateral interaction of the tubes was not eliminated completely, it was decreased substantially and long rigid tubular aggregates were clearly observed in this case (Fig. 3b).

To probe the involvement of the terminal urea moiety in the $\mathrm{H}$-bonding, Fourier transform infrared spectroscopy was utilized for the $\mathrm{C}_{70} / 1$ mixture in $\mathrm{CDCl}_{3}$ (Fig. 3e). The vibrational bands for the terminal $\mathrm{N}-\mathrm{H}$ and carbonyl groups of the urea moiety were unambiguously assigned using an ${ }^{15} \mathrm{~N}$-labelled derivative of $\mathbf{1}$ and model compound $\mathbf{8 a}$, which does not possess the urea group (Supplementary Figs 49 and 50). As seen from Fig. 3e, the addition of $\mathrm{C}_{70}$ to a $\mathrm{CDCl}_{3}$ solution of 1 triggered a remarkable change in the spectrum, namely, the $v(\mathrm{C}=\mathrm{O})$ band of the urea 
a

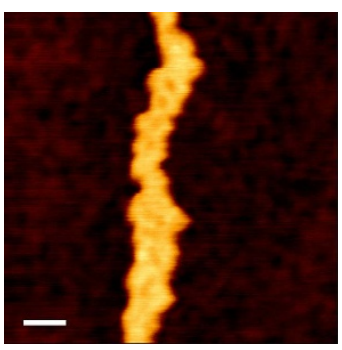

C

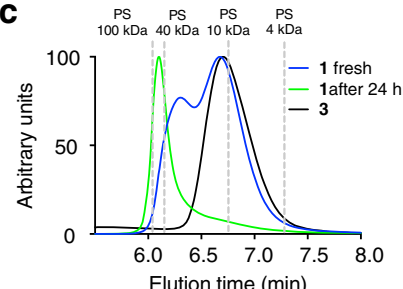

b

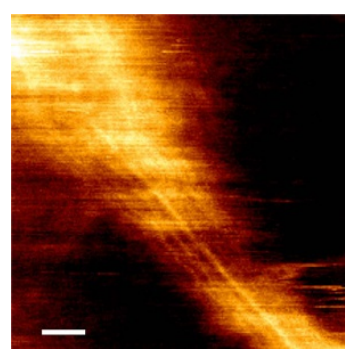

d

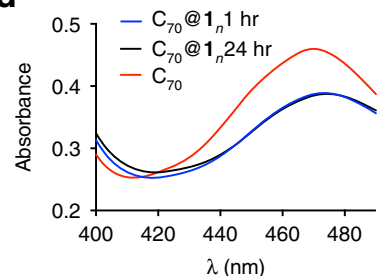

e

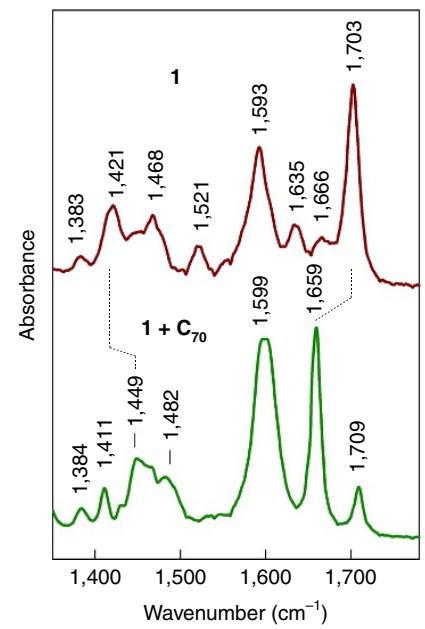

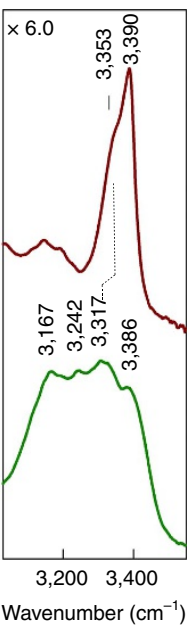

Figure 3 | Characterization of supramolecular tubular polymers. (a) AFM image of $\mathbf{1}$ deposited on silicon surface. (b) AFM image of $\mathbf{2}$ deposited on mica surface. (c) Normalized GPC trace of the solution of $\mathbf{1}$ (fresh and aged) and control compound $\mathbf{3}$ in toluene. The vertical dashed lines correspond to the retention times of polystyrene (PS) standards. (d) Ultraviolet-visible spectra of $C_{70}$ and $C_{70} / \mathbf{1} 1: 4$ mixture in $C_{2 D C}$. (e) Fourier transform infrared spectra of $\mathbf{1}$ (top) and $\mathrm{C}_{70} / \mathbf{1} 1: 4$ mixture (bottom) in $\mathrm{CDCl}_{3}$. Scale bars, $100 \mathrm{~nm}$ (a) and $100 \mathrm{~nm}$ (b).

group in 1 at $1,703 \mathrm{~cm}^{-1}$ downshifted by $44 \mathrm{~cm}^{-1}$, whereas the $v_{\mathrm{a}}(\mathrm{C}-\mathrm{N})$ band at $1,421 \mathrm{~cm}^{-1}$ upshifted by $28 \mathrm{~cm}^{-1}$. Moreover, the $v(\mathrm{~N}-\mathrm{H})$ band downshifted from 3,353 to $3,317 \mathrm{~cm}^{-1}$. All these changes are consistent with the involvement of both the $\mathrm{C}=\mathrm{O}$ and $\mathrm{NH}_{2}$ groups of the urea moiety of $\mathbf{1}$ in the $\mathrm{H}$-bonding interactions.

The two control compounds $\mathbf{3}$ and $\mathbf{4}$ were tested under identical polymerization conditions as for $\mathbf{1}$. In compound $\mathbf{3}$, long decyl chains attached to the nitrogen atom of the pyrrole ring should prevent the polymerization of cyclic units by exerting steric hindrance, whereas in compound 4 the terminal $\mathrm{NH}_{2}$ group of the urea moiety is fully alkylated and is thus incapable of H-bonding. As expected, both control compounds failed to provide supramolecular polymers in the broad range of tested solvents with or without $\mathrm{C}_{70}$ guest added.

Concerning the role of $\mathrm{C}_{70}$ to trigger the polymerization of $\mathbf{1}$, the exact mechanism remains unknown. However, ultravioletvisible studies showed that the $\mathrm{C}_{70}$ molecule is incorporated into the cavity of the tube as evident from the hypochromic effect and the bathochromic shift of the absorption band of $C_{70}$ at $470 \mathrm{~nm}$ by $6 \mathrm{~nm}$ (Fig. 3d). In addition, ${ }^{1} \mathrm{H}$ NMR titration experiments showed that the tubular polymers are saturated with $\mathrm{C}_{70}$ at a molar fraction of 0.25 , corresponding to one $C_{70}$ molecule per cyclic tetramer. It is likely to be that the $\mathrm{C}_{70}$ guests experience attractive forces inside the tube and brings the cyclic tetrameric units together. In fact, the bathochromic shift observed is consistent with a $\mathrm{C}_{70}-\mathrm{C}_{70}$ interaction ${ }^{23,24}$ and is similar to the known attractive interaction of $\mathrm{C}_{60}$ molecules in a confined environment ${ }^{25}$. The polymeric peapod inclusion complexes with $\mathrm{C}_{70}$ so obtained could be attractive for their possible application in the field of organic photovoltaics.

Intrigued by the role of $\mathrm{C}_{70}$ in inducing polymerization of monomer $\mathbf{1}$ in chlorinated solvents, we also probed the effect of $\mathrm{C}_{60}$ guest on the aggregation profile of $\mathbf{1}$ in chloroform. Surprisingly, based on the NMR data, only one well-defined inclusion complex was obtained as opposed to polymeric aggregates with $\mathrm{C}_{70}$. Compared with $\mathbf{1}_{4}$ in $\mathrm{CDCl}_{3}$, each resonance of the $\mathrm{NH}$ protons was split into two upon the addition of $\mathrm{C}_{60}$ (Fig. 4a,b). A single carbon resonance for the $\mathrm{C} 10$ atom provided compelling evidence that symmetry breaking had taken place, resulting in an aggregate composed of one $\mathrm{C}_{1}$-symmetric monomer and not a 1:1 mixture of two $C_{2}$-symmetric monomers (Fig. 4a). Careful analysis of the ${ }^{1} \mathrm{H}$ NMR data revealed two conformers of the PUPy unit, both containing the $6[1 \mathrm{H}]$ pyrimidinone tautomer of the isocytosine ring. Namely, conformer 1 having an intramolecular $\mathrm{H}$-bond between an $\mathrm{N}-\mathrm{H}$ proton in isocytosine and an urea $\mathrm{C}=\mathrm{O}$ group (Fig. 4a, conformer 1) and conformer 2 having an intramolecular $\mathrm{H}$-bond between a urea $\mathrm{N}-\mathrm{H}$ donor and an isocytosine $s p^{2} \mathrm{~N}$ acceptor, as in the original tetramer $\mathbf{1}_{4}$ (Fig. $4 \mathrm{a}$, conformer 2 ). Conformer 1 has never been observed before for PUPy derivatives, whereas in case of UPy derivatives, it is considered detrimental for the dimerization due to its non-self-complementary nature. The cross-peaks between protons $4^{\prime}$ and $6^{\prime}$, and protons $2^{\prime}$ and $5^{\prime}$ in the rotating-frame nuclear Overhauser effect spectrum indicated that these two conformers are located in close proximity to each other and are therefore indicative of an alternating arrangement of these units within the aggregate. Unfortunately, the resonances assigned to terminal protons in the urea moiety, that is, protons $7^{\prime}$ in conformer 1 were too broad to be clearly visible and overlapped with the aromatic ring protons A and B (Fig. 4b). The latter observation and the value of the chemical shift of protons $7^{\prime}$ ( $\delta$ 6.50-7.00 p.p.m.) suggested that they are loosely bound in the aggregate and are exchanging through a rotation of the $\mathrm{CO}-\mathrm{NH}_{2}$ bond. Inspection of molecular models showed that the only possible arrangement of the two conformers that would satisfy the above requirement is in a capsule-like structure, where monomers are arranged side-to-side rather than end-to-end, as in the original tetramer $\mathbf{1}_{4}$ (Fig. 4c). In this way, two terminal urea groups in conformer 2 are $2 \mathrm{H}$-bonded with an additional stabilization by a secondary $\mathrm{H}$-bond from the isocytosine $\mathrm{N}-\mathrm{H}$ donor located in the proximity. To this dimer, two conformers 1 are attached at both ends via H-bond between the urea proton $6^{\prime}$ and the carbonyl group of the isocytosine ring and between the carbonyl group of the urea moeity and proton $2^{\prime}$ in the other conformer (Fig. 4d). The protons $7^{\prime}$ are only weakly bound to the carbonyl groups of isocytosine and urea moieties of conformer 2 and as a result of geometric constrains they are slightly bended out from the plane of the $\mathrm{H}$-bonding interface, in agreement with the broadening of the corresponding $\mathrm{NH}$ resonances observed in ${ }^{1} \mathrm{H}$ NMR (Fig. 4b). In addition, the large upfield shift of the isocytosine $\mathrm{NH}$ proton $4^{\prime}$ of conformer 2 in the complex $\mathrm{C}_{60} @ \mathbf{1}_{4}$ 
a

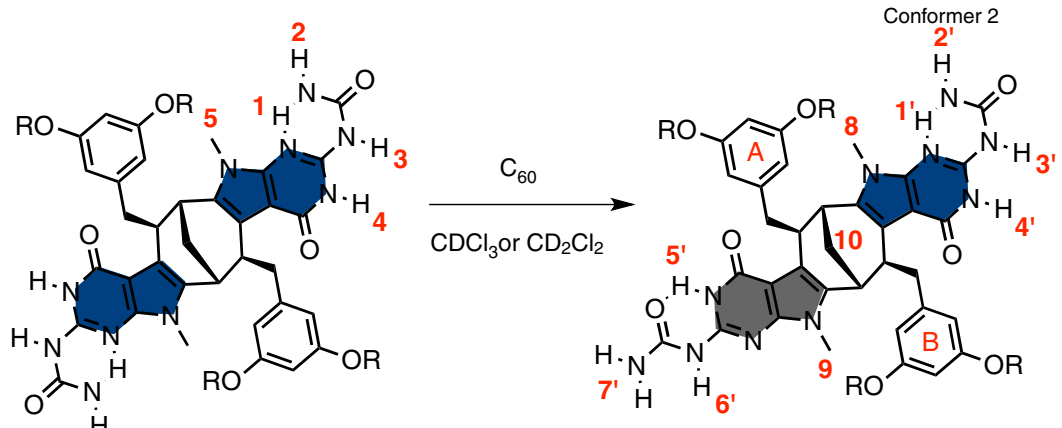

$\mathrm{H}$

b $\quad \mathbf{1}_{4} \mathrm{CDCl}_{3}$

Conformer 1

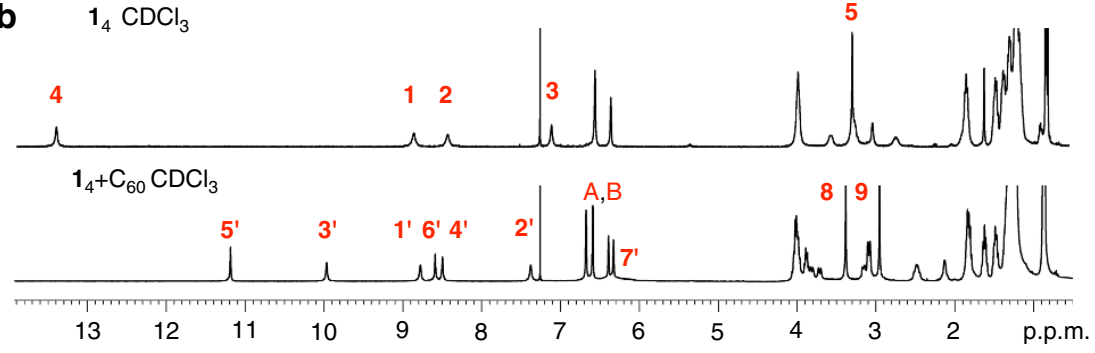

C

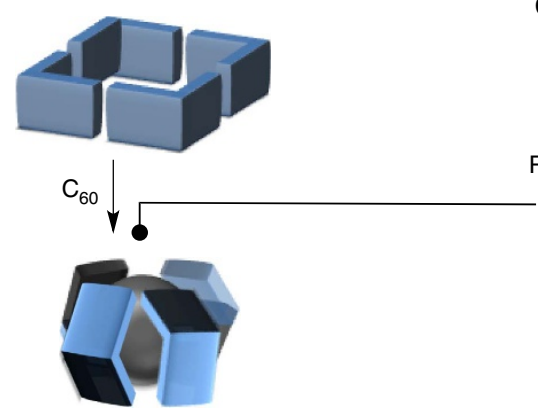

e

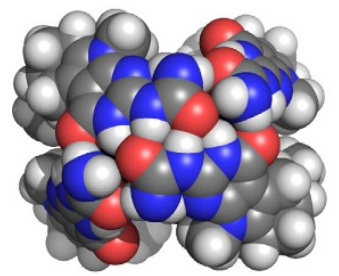

Top d

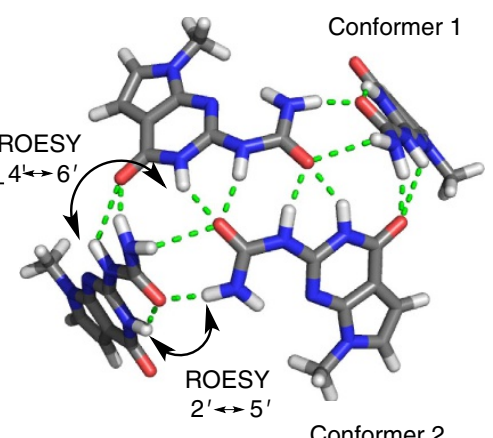

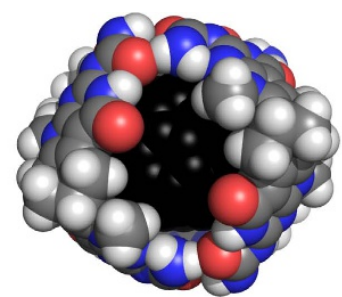

Side 1

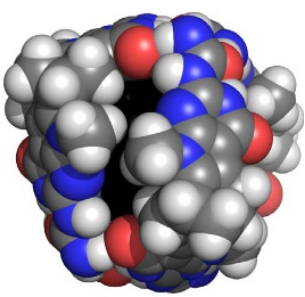

Side 2

Figure 4 | Structure of the insertion complex $\mathbf{C}_{\mathbf{6 0}} @ \mathbf{1}_{\mathbf{4}}$. (a) Symmetry breaking of monomer $\mathbf{1}$ by conformer redistribution in PUPy units. Conformer 1 (grey) and conformer 2 have the same 6[1H]-pyrimidinone tautomeric form but different intramolecular $\mathrm{H}$-bonds. (b) ${ }^{1} \mathrm{H}$ NMR spectrum of $\mathbf{1}_{4}$ (top) and $\mathrm{C}_{60} @ \mathbf{1}_{4}$ (bottom). (c) Schematic representation of starting tetramer $\mathbf{1}_{4}$ and capsular complex $\mathrm{C}_{60} @ \mathbf{1}_{4}$. (d) Top view of H-bonding interface between two conformers of PUPy with rotating-frame nuclear Overhauser effect interactions indicated. H-bonds are presented by dashed green lines. (e) Top and side views of the optimized molecular models of $\mathrm{C}_{60} @ \mathbf{1}_{4}$. Carbons in $\mathrm{C}_{60}$ molecule are labelled black.

is in accord with its much weaker out-of-plane intermolecular $\mathrm{H}$-bonding with the carbonyl group of the urea moiety as opposed to nearly optimal H-bonding in the free tetramer $\mathbf{1}_{4}$ (Fig. $4 \mathrm{~b}, \mathrm{~d})$. The 4:1 $\left(\mathbf{1}: \mathrm{C}_{60}\right)$ stoichiometry of the complex was determined from molar-ratio method using ${ }^{1} \mathrm{H} \quad \mathrm{NMR}$ (Supplementary Fig. 61) and is also in line with an even number of monomers required for their symmetric alternating arrangement within the aggregate. Moreover, the control compound 3 with bulkier decyl groups on the pyrrole ring was not able to form the corresponding capsule-like insertion complex due to very unfavourable intermolecular steric interactions between decyl chains (Fig. 4e, Side 2). The other control compound 4 did not interact with $\mathrm{C}_{60}$ either, because the corresponding capsule cannot form without $\mathrm{H}$-bond donors on the terminal urea group (Fig. 4d). According to molecular modelling (Supplementary Fig. 62), the capsule embraces the $C_{60}$ guest $(d=0.71 \mathrm{~nm})$ so tightly that having the same diameter but being only slightly longer $C_{70}\left(d_{1}=0.712 \mathrm{~nm}, d_{2}=0.796 \mathrm{~nm}\right)$ is already too large to fit into the cavity and thus the formation of this type of capsule is no longer possible. For this reason, an inclusion complex with $\mathrm{C}_{70}$ was first formed with an open form of the $\mathbf{1}_{4}$ tetramer, which ultimately led to polymers $\left(\mathrm{C}_{70} @ \mathbf{1}_{4}\right)_{n}$ via rim-to-rim aggregation 
of $\mathrm{C}_{70} @ \mathbf{1}_{4}$ (Fig. 2d). The affinity of the host $\mathbf{1}$ for $\mathrm{C}_{60}$ and $\mathrm{C}_{70}$ was found to be very similar based on the liquid-solid extraction studies (Supplementary Table 2). The system described above represents a responsive and sensitive supramolecular system for the fine-tuning between different open and closed tubular topologies. The distinctive spatial arrangement of the $\mathrm{H}$-bonding sites and the possibility for the interconversion of conformers are the hallmarks of this system.

Systems chemistry of tubular aggregates. The facile switch between polymeric supramolecular tubes and well-defined capsules by guest or solvent stimuli encouraged us to devise an even more complex multicomponent supramolecular system with an external modulator of the guest ${ }^{26,27}$. For this purpose, the known $\mathrm{C}_{2}$-symmetric bicyclic monomer 9 (Fig. 5), composed of the BCN scaffold and two UPy derivatives fused to its termini was used ${ }^{12}$. From our previous studies, it is well-established that monomer 9 forms a cyclic tetrameric aggregate $\mathbf{9}_{4}$, which does not interact with a $\mathrm{C}_{60}$ guest in $\mathrm{CDCl}_{3}$ (ref. 12). However, after changing the solvent to toluene, $\mathbf{9}_{4}$ becomes a very efficient host for fullerenes and thus it might act as a $\mathrm{C}_{60}$ scavenger. Cycling between the solvents chloroform and toluene for the $9_{4} / C_{60}$ mixture would then represent a convenient switching system for $\mathrm{C}_{60}$ catchrelease (ON/OFF) events provided that aggregate $\mathbf{9}_{4}$ is narcissistically self-sorted ${ }^{28,29}$ in the presence of monomer $\mathbf{1}$ and has higher affinity for $\mathrm{C}_{60}$ compared with tubular polymers $\left(\mathbf{1}_{4}\right)_{\mathrm{n}}$.

To implement the above design elements into a functional system, we then first probed the self-sorting properties of monomer 1 and 9 in $\mathrm{CDCl}_{3}$ solution. As seen from Fig. $5 \mathrm{~d}$ (process A), the ${ }^{1} \mathrm{H}$ NMR experiment revealed that no exchange of monomers between two tetrameric assemblies $\mathbf{1}_{4}$ and $\mathbf{9}_{4}$ (1:1 mixture) took place, indicating high fidelity of the UPy and PUPy units for homoaggregation. The addition of 0.25 eq. of $\mathrm{C}_{60}$, resulted in the selective formation of a capsular inclusion complex $\mathrm{C}_{60} @ \mathbf{1}_{4}$, leaving $\mathbf{9}_{4}$ intact (Fig. 5e, process B). The identity of all species was confirmed by comparing the corresponding ${ }^{1} \mathrm{H}$ NMR spectrum of the mixture to the ones of separately prepared samples (Fig. $5 \mathrm{c}, \mathrm{e}$ ). When $\mathrm{CDCl}_{3}$ was replaced for toluene- $d_{8}$, the inclusion capsule $\mathrm{C}_{60} @ \mathbf{1}_{4}$ rearranged into the tubular polymer of $\mathbf{1}_{4}$, whereas concomitantly the $\mathrm{C}_{60}$ guest moved into the cavity of 9. (Fig. 5g, process C). The emergence of characteristic resonances attributed to $\mathrm{C}_{60} @ 9_{4}$ were clearly observed in the ${ }^{1} \mathrm{H}$ NMR spectrum, whereas the formation of $\left(\mathbf{1}_{4}\right)_{n}$ was evidenced by the broadening and the eventual disappearance of all $\mathrm{NH}$ resonances corresponding to $\mathrm{C}_{60} @ \mathbf{1}_{4}$ (Fig. 5g,e). The higher stability of complex $\mathrm{C}_{60} @ 9_{4}$ in comparison with possible peapod complexes $\left(\mathrm{C}_{60}\right)_{m}\left(\mathbf{1}_{4}\right)_{n}$, is a direct effect of a perfect match of sizes between $\mathrm{C}_{60}$ and the cavity of $\mathbf{9}_{4}$. The whole process is fully reversible and after switching the solvent from toluene- $d_{8}$ back to $\mathrm{CDCl}_{3}$, the initial state, $\mathrm{C}_{60} @ \mathbf{1}_{4} / \mathbf{9}_{4}$, was recovered. The swapping of the $\mathrm{C}_{60}$ guest in the present supramolecular system guarantees that only one host is empty (disregarding the solvent molecules) at the time and may find applications as a selective switch in a future generation of more complex systems where a larger number of guests are present.

\section{Discussion}

In conclusion, this study provides an example of a sophisticated dynamic tubular $\mathrm{H}$-bonded system generated from one single type of small, highly preorganized monomer (1). The monomer easily changes its aggregation mode in response to the solvent or guest in a unique manner, resulting in an open-ended cyclic structure, a closed shell capsule or polymeric tubular assemblies. For the first time, molecular tubes were assembled between small organic molecules, where both the cyclic framework and the polymerization were accomplished by H-bonding. This was achieved using a monomer containing a non-self-complementary form of UPy derivative fused with an electron-rich pyrrole ring. Besides the control of the polymerization by the nature of the solvent, also the formation of tubular polymeric inclusion complex was demonstrated by the addition of $\mathrm{C}_{70}$ guest molecules. Owing to the ordered arrangement of electron conductive $\mathrm{C}_{70}$ molecules within the tube, these assemblies can be considered for their potential implementation into organic photovoltaic devices. In addition, the highly dynamic nature of monomer 1 was revealed in the formation of a capsule-like complex with a $\mathrm{C}_{60}$ guest, where two different conformers embedded within a single monomer were interacting. These modes for the self-assembly of structurally simple monomers open new possibilities to easily create stimuli-responsive, complex multicomponent systems of different topologies.

\section{Methods}

Materials and characterization. All chemicals were used as received from commercial suppliers. All moisture-sensitive reactions were carried out under an atmosphere of dry nitrogen using oven-dried glassware. ${ }^{1} \mathrm{H} \mathrm{NMR}(400 \mathrm{MHz})$ and ${ }^{13} \mathrm{C}$ NMR $(100 \mathrm{MHz})$ were recorded on a Bruker Ascend spectrometer. Chemical shifts are given in parts per million relative to the residual solvent signals at $\delta=7.27\left({ }^{1} \mathrm{H}\right.$ NMR) and $77.16\left({ }^{13} \mathrm{C} \mathrm{NMR}\right)$ p.p.m. in $\mathrm{CDCl}_{3}$ and $\delta=7.00\left({ }^{1} \mathrm{H} \mathrm{NMR}\right)$ and $128.33\left({ }^{13} \mathrm{C}\right.$ NMR) p.p.m. in toluene- $d_{8}$. Enantiomeric excess was determined with a Perkin-Elmer Autosystem XL Gas Chromatograph using Alpha DEXTM 120 fused silica capillary column. Elemental analysis was performed at A. Kolbe Mikroanalytisches Laboratorium, Germany, and Microanalysis Laboratory in Department of Organic Chemistry, Vilnius University.

Synthesis of 7a. A suspension of compound $\mathbf{5 a}(3.17 \mathrm{~g}, 3.31 \mathrm{mmol}, 1.0$ eq.) and 2-amino-6-(1-methylhydrazinyl)-4(3H)-pyrimidinone 6 (1.32 g, $8.51 \mathrm{mmol}, 2.6$ eq.) in acetic acid $(185 \mathrm{ml})$ was stirred at room temperature. After $19 \mathrm{~h}$, the solvent was removed under reduced pressure at $30^{\circ} \mathrm{C}$. Toluene was used to remove residues of acetic acid. Then, it was dried under high vacuum overnight and subjected to flash chromatography. Elution with gradient eluent system $\left(\mathrm{CH}_{2} \mathrm{Cl}_{2} / \mathrm{MeOH}+\right.$ $\left.1 \% \mathrm{Et}_{3} \mathrm{~N}, 100 / 1,60 / 1,40 / 1,30 / 1,20 / 1\right)$ afforded $2.81 \mathrm{~g}$ (69\% yield) of compound 7a. Compound 7 a was obtained as a mixture of $E$ and $Z$ isomers, which gave a very complicated ${ }^{1} \mathrm{H}$ NMR spectrum. For this reason, full characterization of 7 a was not attempted and the compound was used directly in the next step.

HRMS (ESI) calcd. for $\left([\mathrm{M}+\mathrm{H}]^{+}\right): \mathrm{C}_{73} \mathrm{H}_{119} \mathrm{~N}_{10} \mathrm{O}_{6}$ 1231.9314; Found: 1231.9343 .

Synthesis of 8a. A solution of compound $7 \mathbf{a}(2.50 \mathrm{~g}, 2.0 \mathrm{mmol})$ in diphenyl ether $(95 \mathrm{ml})$ was heated to reflux with an air condenser passing nitrogen stream through the mixture via a long cannula. After $29 \mathrm{~h}$, the evolution of ammonia ceased and the reaction mixture was cooled to room temperature. The reaction mixture was directly loaded on the silica gel column and diphenyl ether was removed by using petroleum ether as eluent. Then, the eluent was changed to $\mathrm{CH}_{2} \mathrm{Cl}_{2} / \mathrm{MeOH}(10 / 1)$, to afford $2.34 \mathrm{~g}$ of partially purified product. The crude product was further purified by flash chromatography with gradient eluent system $\left(\mathrm{CH}_{2} \mathrm{Cl}_{2}\right.$, then $\mathrm{CH}_{2} \mathrm{Cl}_{2} /$ $\mathrm{MeOH} 100 / 1,80 / 1,50 / 1,30 / 1,20 / 1)$ to afford $1.65 \mathrm{~g}$ (68\% yield) of compound $8 \mathbf{a}$ as a yellowish glass. ${ }^{1} \mathrm{H}$ NMR $\left(400 \mathrm{MHz}, \mathrm{CDCl}_{3}\right) \delta 12.90$ (br. s, $\left.1 \mathrm{H}\right), 6.60$ $(\mathrm{d}, J=4.0 \mathrm{~Hz}, 2 \mathrm{H}), 6.34(\mathrm{~s}, 1 \mathrm{H}), 4.71(\mathrm{~s}, 2 \mathrm{H}), 3.93(\mathrm{t}, J=8.0 \mathrm{~Hz}, 4 \mathrm{H}), 3.52$ $(\mathrm{d}, J=8.0 \mathrm{~Hz}, 1 \mathrm{H}), 3.02-3.08(\mathrm{~m}, 2 \mathrm{H}), 2.98(\mathrm{~s}, 3 \mathrm{H}), 2.42(\mathrm{t}, J=12 \mathrm{~Hz}, 1 \mathrm{H}), 2.08$ (s, $1 \mathrm{H}), 1.72-1.79(\mathrm{~m}, 4 \mathrm{H}), 1.40-1.44(\mathrm{~m}, 4 \mathrm{H}), 1.26-1.31(\mathrm{~m}, 24 \mathrm{H}), 0.87$ $(\mathrm{t}, J=8.0 \mathrm{~Hz}, 6 \mathrm{H}) ;{ }^{13} \mathrm{C} \mathrm{NMR}\left(100 \mathrm{MHz}, \mathrm{CDCl}_{3}\right) \delta 161.55,160.39,151.47,151.12$, $144.45,131.5,113.04,108.40,98.72,98.57,68.16,41.59,41.59,32.03,29.73,29.71$, $29.58,29.54,29.46,27.66,27.33,26.24,22.82,21.37,14.26$; IR $v_{\max } / \mathrm{cm}^{-1}$ (in $\mathrm{CDCl}_{3}$ ) 3,507, 3,406, 1,664, 1,634, 1,596, 1,460; HRMS (ESI) calcd. for ([M+ $\left.\mathrm{H}]^{+}\right): \mathrm{C}_{73} \mathrm{H}_{113} \mathrm{~N}_{8} \mathrm{O}_{6}$ 1197.8783; Found: 1197.8761; Anal. calcd. for $\mathrm{C}_{73} \mathrm{H}_{112} \mathrm{~N}_{8} \mathrm{O}_{6} \cdot 1 / 5 \mathrm{CH}_{2} \mathrm{Cl}_{2}$ : C, 72.38; H, 9.33; N, 9.22; Found: C, 72.54; H, 9.34; N, 8.83 .

Synthesis of 1. Compound $8 \mathrm{a}(0.53 \mathrm{~g}, 0.44 \mathrm{mmol}, 1.0 \mathrm{eq}$.) was dissolved in anhydrous pyridine $(30 \mathrm{ml})$ under $\mathrm{N}_{2}$ and the solution obtained was cooled in an ice bath. Then PhOCOCl $(0.61 \mathrm{ml}, 4.86 \mathrm{mmol}, 11.0$ eq. $)$ was added dropwise. After $10 \mathrm{~min}$, the ice bath was removed and the reaction mixture was stirred at room temperature for $22 \mathrm{~h}$. Then it was cooled to $0{ }^{\circ} \mathrm{C}$ again and $25 \% \mathrm{NH}_{3}$ (aq.) $(2.8 \mathrm{ml})$ was added dropwise. The resulting mixture was allowed to reach room temperature and stirred overnight. The suspension was quenched with excess of $10 \% \mathrm{HCl}$ and extracted with $\mathrm{CH}_{2} \mathrm{Cl}_{2}$. The combined organic phase was washed with sat. $\mathrm{NaHCO}_{3}$, dried with $\mathrm{Na}_{2} \mathrm{SO}_{4}$ and evaporated. The residue was triturated with $\mathrm{MeOH}(300 \mathrm{ml})$ and sonicated for several minutes. The suspension was filtered to 
a

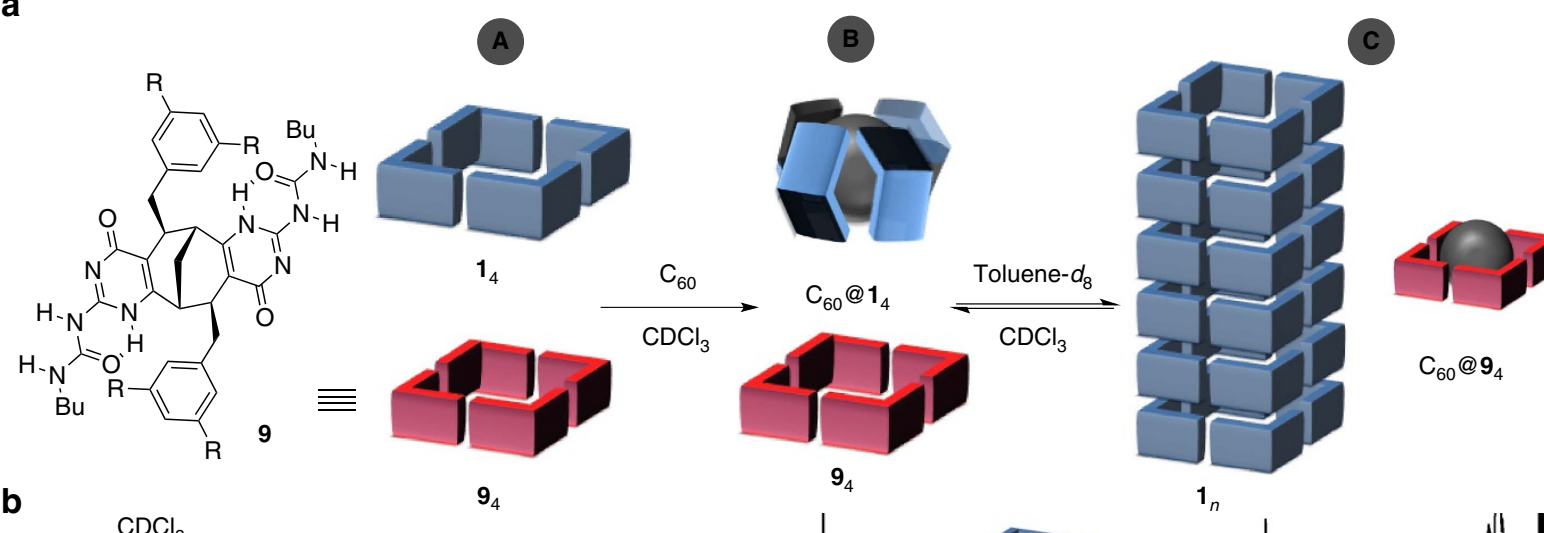

b

$\mathrm{CDCl}_{3}$

$9_{4}$

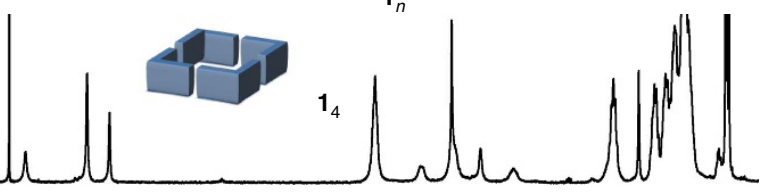

C
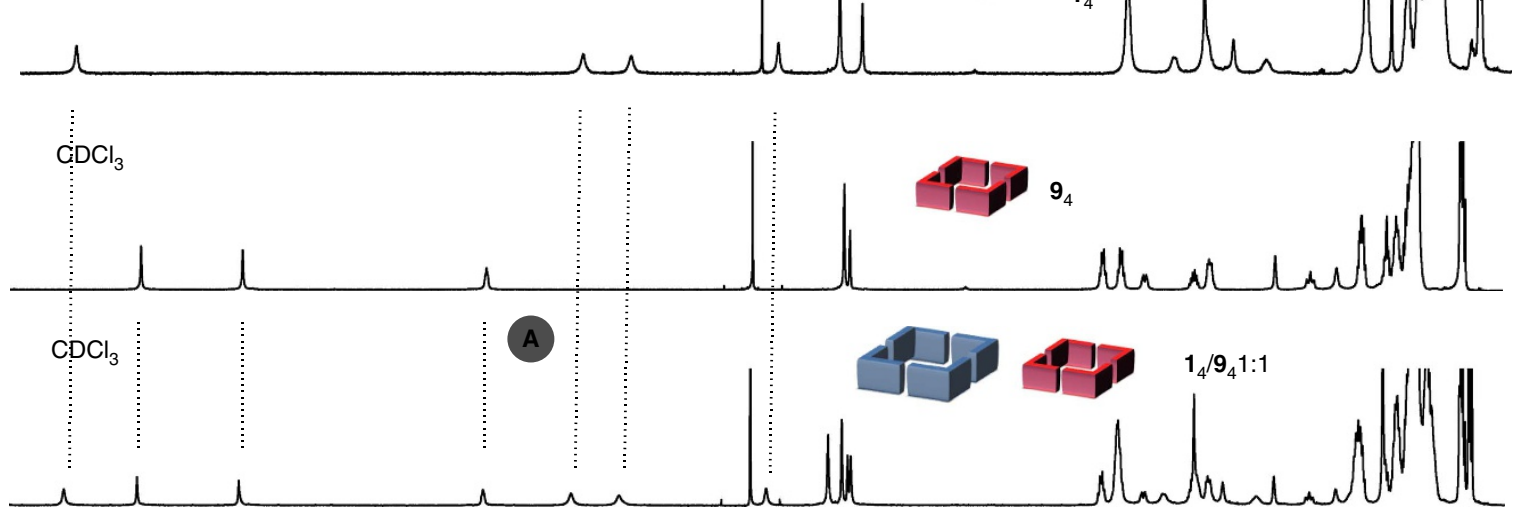

d

e

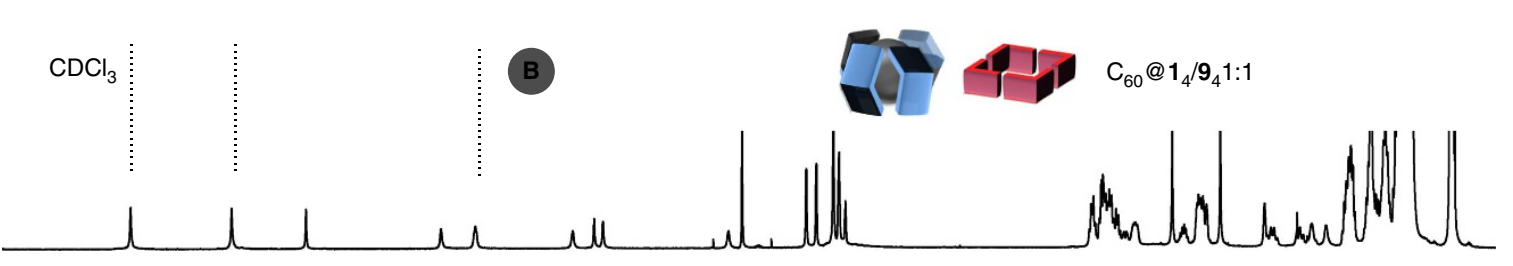

$\mathbf{f}$

$\mathrm{CDCl}_{3}$

$\mathbf{g}$
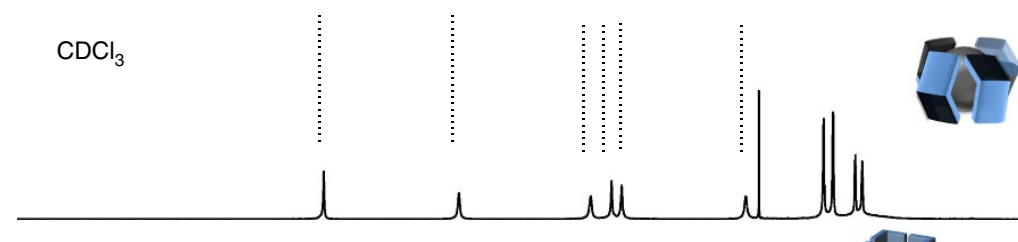

$\mathrm{C}_{60} @ \mathbf{1}_{4}$

Toluene- $d_{8}$

$\mathbf{h}$

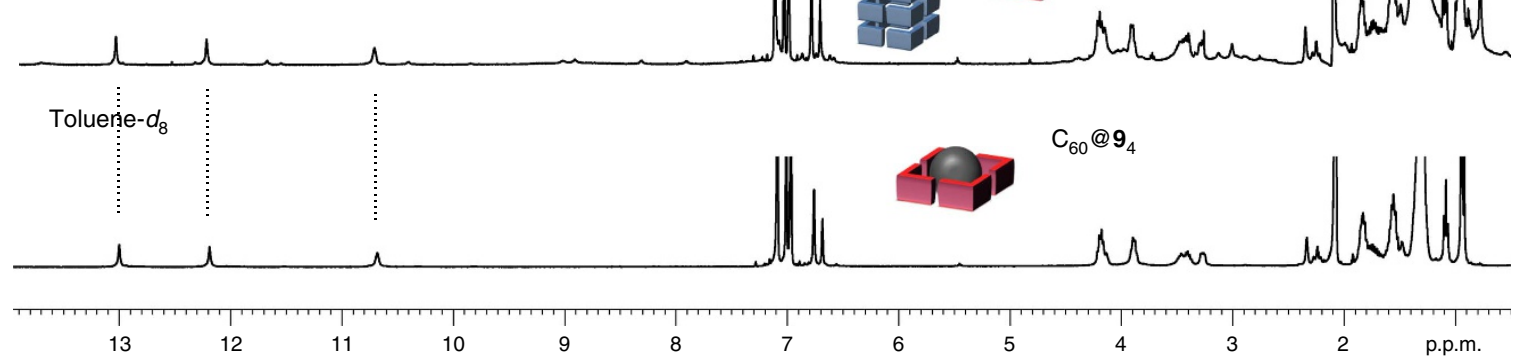

Figure 5 | Self-sorting studies and ${ }^{\mathbf{1}} \mathbf{H}$ NMR spectra of three-component supramolecular system. (a) Chemical structure of $4 \mathrm{H}$-bonding monomer 9 and schematic representation of self-sorting (process $A$ ), selective encapsulation of $C_{60}$ guest (process $B$ ) and capsule-tube isomerization (process $C$ ). (b) ${ }^{1} \mathrm{H}$ NMR spectrum of $\mathbf{1}_{4}$ in $\mathrm{CDCl}_{3}$. (c) ${ }^{1} \mathrm{H}$ NMR spectrum of $\mathbf{9}_{4}$ in $\mathrm{CDCl}_{3}$. (d) ${ }^{1} \mathrm{H}$ NMR spectrum of 1:1 mixture of $\mathbf{1}_{4}$ and $\mathbf{9}_{4}$ in $\mathrm{CDCl}{ }_{3}$ (process $\mathrm{A}$ ). (e) ${ }^{1} \mathrm{H}$ NMR spectrum of $\mathrm{C}_{60} @ \mathbf{1}_{4}$ and $\mathbf{9}_{4}$ in $\mathrm{CDCl}_{3}$ after addition of 0.25 eq. of $\mathrm{C}_{60}$ (process B). (f) ${ }^{1} \mathrm{H}$ NMR spectrum of $\mathrm{C}_{60} @ \mathbf{1}_{4}$ in $\mathrm{CDCl}_{3}$. $(\mathbf{g})^{1} \mathrm{H}$ NMR spectrum of $\left(\mathbf{1}_{4}\right)_{n}$ and $\mathrm{C}_{60} @ \mathbf{9}_{4}$ in toluene- $d_{8}$ (process $\mathrm{C}$ ). (h) ${ }^{1} \mathrm{H}$ NMR spectrum of $\mathrm{C}_{60} @ \mathbf{9}_{4}$ in toluene- $d_{8}$. 
give $0.43 \mathrm{~g}$ (77\% yield) of compound $\mathbf{1}$ as an off-white solid. ${ }^{1} \mathrm{H}$ NMR $(400 \mathrm{MHz}$, $\left.\mathrm{CDCl}_{3}\right) \delta 13.43(\mathrm{~s}, 1 \mathrm{H}), 8.88(\mathrm{~s}, 1 \mathrm{H}), 8.44(\mathrm{~s}, 1 \mathrm{H}), 7.12(\mathrm{~s}, 1 \mathrm{H}), 6.56(\mathrm{~s}, 2 \mathrm{H}), 6.36$ (s, $1 \mathrm{H}), 3.97$ (br. s, $4 \mathrm{H}), 3.55(\mathrm{~d}, J=8.0 \mathrm{~Hz}, 1 \mathrm{H}), 3.28(\mathrm{~m}, 4 \mathrm{H}), 3.02(\mathrm{~s}, 1 \mathrm{H}), 2.72$ (br. s, $1 \mathrm{H}), 1.81-1.84(\mathrm{~m}, 5 \mathrm{H}), 1.15-1.45(\mathrm{~m}, 28 \mathrm{H}), 0.80(\mathrm{t}, J=8.0 \mathrm{~Hz}, 6 \mathrm{H}) ;{ }^{13} \mathrm{C}$ NMR $\left(100 \mathrm{MHz}, \mathrm{CDCl}_{3}\right) \delta 160.29,160.01,156.72,147.80,145.20,143.46,132.67$, $114.01,108.15,101.35,99.18,68.09,41.44,40.18,31.99,29.87,29.75,29.70,29.53$, 29.43, 28.30, 28.30, 26.24, 22.77, 20.99, 14.18; IR $v_{\max } / \mathrm{cm}^{-1}\left(\right.$ in $\mathrm{CDCl}_{3}$ ) 3,390, $3,353,1,703,1,593,1,468,1,421$; HRMS (ESI) calcd. for $\left([\mathrm{M}+\mathrm{H}]^{+}\right)$:

$\mathrm{C}_{75} \mathrm{H}_{115} \mathrm{~N}_{10} \mathrm{O}_{8}$ 1283.8899; Found: 1283.8911; Anal. calcd. for $\mathrm{C}_{75} \mathrm{H}_{114} \mathrm{~N}_{10} \mathrm{O}_{8}$ : C,

70.17; H, 8.95; N, 10.91; Found: C, 70.01; H, 8.92; N, 10.86

For further information on Methods, see the Supplementary Information.

Data availability. The authors declare that the data supporting the findings of this study are available within the paper and its Supplementary Information file.

\section{References}

1. Hof, F., Craig, S. L., Nuckolls, C. \& Rebek, Jr J. Molecular encapsulation. Angew. Chem. Int. Ed. 41, 1488-1508 (2002).

2. Block, M. A. B., Kaiser, C., Khan, A. \& Hecht, S. Discrete organic nanotubes based on a combination of covalent and non-covalent approaches. Top. Curr. Chem. 245, 89-150 (2005).

3. Sun, Q.-F. et al. Self-assembled $\mathrm{M}_{24} \mathrm{~L}_{48}$ polyhedra and their sharp structural switch upon subtle ligand variation. Science 328, 1144-1147 (2010).

4. Tiefenbacher, K., Ajami, D. \& Rebek, Jr J. Self-assembled capsules of unprecedented shapes. Angew. Chem. Int. Ed. 50, 12003-12007 (2011).

5. Bong, D. T., Clark, T. D., Granja, J. R. \& Ghadiri, M. R. Self-assembling organic nanotubes. Angew. Chem. Int. Ed. 40, 988-1011 (2001).

6. Dalgarno, S. J., Cave, G. W. V. \& Atwood, J. L. Toward the isolation of functional organic nanotubes. Angew. Chem. Int. Ed. 45, 570-574 (2006).

7. Stončius, S. et al. An approach to helical tubular self-aggregation using $\mathrm{C}_{2}$-symmetric self-complementary hydrogen-bonding cavity molecules. J. Am. Chem. Soc. 128, 8272-8285 (2006).

8. Ponnuswamy, N., Stefankiewicz, A. R., Sanders, J. K. M. \& Pantoş, G. D. Supramolecular naphthalenediimide nanotubes. Top. Curr. Chem. 322, 217-260 (2012).

9. Beijer, F. H., Sijbesma, R. P., Kooijman, H., Spek, A. L. \& Meijer, E. W. Strong dimerization of ureidopyrimidones via quadruple hydrogen bonding. J. Am. Chem. Soc. 120, 6761-6769 (1998).

10. Sijbesma, R. P. \& Meijer, E. W. Quadruple hydrogen bonded systems. Chem. Commun. 2003, 5-16 (2003).

11. Brunsveld, L., Folmer, B. J. B., Meijer, E. W. \& Sijbesma, R. P. Supramolecular polymers. Chem. Rev. 101, 4071-4097 (2001).

12. Shi, Q. et al. Composition- and size-controlled cyclic self-assembly by solventand $\mathrm{C}_{60}$-responsive self-sorting. J. Am. Chem. Soc. 135, 15263-15268 (2013).

13. Huerta, E. et al. Selective binding and easy separation of $C_{70}$ by nanoscale selfassembled capsules. Angew. Chem. Int. Ed. 46, 202-205 (2007).

14. Beckers, E. H. A. et al. Singlet-energy transfer in quadruple hydrogen-bonded oligo(p-phenylenevinylene)-fullerene dyads. J. Mater. Chem. 12, 2054-2060 (2002)

15. Dankers, P. Y. W., Harmsen, M. C., Brouwer, L. A., Van Luyn, M. J. A. \& Meijer, E. W. A modular and supramolecular approach to bioactive scaffolds for tissue engineering. Nat. Mater. 4, 568-574 (2005).

16. Park, T., Todd, E. M., Nakashima, S. \& Zimmerman, S. C. A quadruply hydrogen bonded heterocomplex displaying high-fidelity recognition. J. Am. Chem. Soc. 127, 18133-18142 (2005).

17. Wallentin, C.-J., Orentas, E., Butkus, E. \& Wärnmark, K. Baker's yeast for sweet dough enables large-scale synthesis of enantiomerically pure bicyclo[3.3.1]nonane-2,6-dione. Synthesis 2009, 864-867 (2009).

18. Orentas, E. et al. Topology selection and tautoleptic aggregation: formation of an enantiomerically pure supramolecular belt over a helix. Angew. Chem. Int. Ed. 50, 2071-2074 (2011).

19. Račkauskaite, D., Gegevičius, R., Matsuo, Y., Wärnmark, K. \& Orentas, E. An enantiopure hydrogen-bonded octameric tube: self-sorting and guest-induced rearrangement. Angew. Chem. Int. Ed. 55, 208-212 (2016).

20. Račkauskaite, D. et al. A remarkably complex supramolecular hydrogenbonded decameric capsule formed from an enantiopure $C_{2}$-symmetric monomer by solvent-responsive aggregation. J. Am. Chem. Soc. 137, 10536-10546 (2015)

21. Orentas, E., Bagdžiūnas, G., Berg, U., Žilinskas, A. \& Butkus, E. Enantiospecific synthesis and chiroptical properties of bicyclic enones. Eur. J. Org. Chem. 2007, 4251-4256 (2007).

22. Lee, E., Jung-Keun, K. \& Lee, M. Tubular stacking of water-soluble toroids triggered by guest encapsulation. J. Am. Chem. Soc. 131, 18242-18243 (2009).

23. Wang, Y. M., Kamat, P. V. \& Patterson, L. K. Aggregates of $\mathrm{C}_{60}$ and $\mathrm{C}_{70}$ formed at the gas-water interface and in $\mathrm{DMSO} /$ water mixed solvents. A spectral study. J. Phys. Chem. 97, 8793-8797 (1993).

24. Ghosh, H. N., Sapre, A. V. \& Mittal, J. P. Aggregation of $\mathrm{C}_{70}$ in solvent mixtures. J. Phys. Chem. 100, 9439-9443 (1996).

25. Wietor, J.-L., Pantoş, G. D. \& Sanders, J. K. M. Templated amplification of an unexpected receptor for $\mathrm{C}_{70}$. Angew. Chem. Int. Ed. 47, 2689-2692 (2008).

26. Ludlow, R. F. \& Otto, S. Systems chemistry. Chem. Soc. Rev. 37, 101-108 (2008).

27. Mattia, E. \& Otto, S. Supramolecular systems chemistry. Nat. Nanotechnol. 10, 111-119 (2015)

28. Wu, A. \& Isaacs, L. Self-sorting: the exception or the rule? J. Am. Chem. Soc. 125, 4831-4835 (2003).

29. Safont-Sempere, M. M., Fernández, G. \& Würthner, F. Self-sorting phenomena in complex supramolecular systems. Chem. Rev. 111, 5784-5814 (2011).

\section{Acknowledgements}

Q.S. acknowledges the Wenner-Gren Foundation for a post-doc fellowship. K.W. thanks the Royal Physiographic Society in Lund for financial support. E.O. acknowledges support from European Social Fund under Global Grand Measure (VP1-3.1-ŠMM-07-K-03007). A.U. acknowledges support from Research Council of Lithuania under the grant agreement MIP-053/2014. Dr Jiaying Liu is acknowledged for help with HPLC measurements.

\section{Author contributions}

E.O. and K.W. contributed equally in conceiving the idea, designing the experiments and writing the manuscript, and are listed in alphabetical order. Q.S. and T.J. synthesized and characterized the compounds. K.-E.B. performed NMR experiments. A.U. performed AFM experiments. G.N. and I.M. performed Fourier transform infrared spectroscopic studies. All authors commented on the final draft of the manuscript and contributed to the analysis and interpretation of the data.

\section{Additional information}

Supplementary Information accompanies this paper at http://www.nature.com/ naturecommunications

Competing interests: The authors declare no competing financial interests.

Reprints and permission information is available online at http://npg.nature.com/ reprintsandpermissions/

How to cite this article: Shi, Q. et al. Stimuli-controlled self-assembly of diverse tubular aggregates from one single small monomer. Nat. Commun. 8, 14943 doi: 10.1038/ ncomms14943 (2017)

Publisher's note: Springer Nature remains neutral with regard to jurisdictional claims in published maps and institutional affiliations.

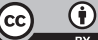

This work is licensed under a Creative Commons Attribution 4.0 International License. The images or other third party material in this article are included in the article's Creative Commons license, unless indicated otherwise in the credit line; if the material is not included under the Creative Commons license, users will need to obtain permission from the license holder to reproduce the material To view a copy of this license, visit http://creativecommons.org/licenses/by/4.0/

C) The Author(s) 2017 